Original Research Paper

\title{
Facile Synthesis of AgCl Hollow Nanospheres for Enhanced Photocatalytic Properties
}

\author{
${ }^{1}$ Jing Chen, ${ }^{1}$ Yuling Zhao, ${ }^{1}$ Xinhui Liu, ${ }^{1}$ Fang Li and ${ }^{2}$ Haisheng Qian \\ ${ }^{I}$ Department of Chemistry, Zhejiang Normal University, Jinhua 321004, P.R. China \\ ${ }^{2}$ School of Medical Engineering, Hefei University of Technology, Hefei 230009, P.R. China
}

\author{
Article history \\ Received: 16-04-2015 \\ Revised: 9-5-2015 \\ Accepted: 19-5-2015 \\ Corresponding Authors: \\ Haisheng Qian \\ School of Medical Engineering, \\ Hefei University of Technology, \\ Hefei 230009, P. R. China \\ Emails: shqian@hfut.edu.cn
}

\begin{abstract}
AgCl}$ hollow nanospheres have been synthesized successfully via a hard-template approach using silica nanospheres as hard template for the first time. The phase, size and morphology of the as-prepared $\mathrm{AgCl}$ were investigated by X-Ray Diffraction (XRD), Field-Emission Scanning Electron Microscopy (FESEM); which reveals that the cubic $\mathrm{AgCl}$ hollow nanospheres with a cell constant a $=5.549 \AA$ are $220 \mathrm{~nm}$ in diameter and $10 \mathrm{~nm}$ of shell-thickness. The as-prepared $\mathrm{AgCl}$ hollow nanospheres demonstrate enhanced photodegradation of Rhodamine $(\mathrm{RhB})$ under visible light irradiation than $\mathrm{AgCl}$ microparticles. The $\mathrm{AgCl}$ hollow nanospheres are of great importance to wide application in catalysis, drug delivery and nanobiotechnology.
\end{abstract}

Keywords: Inorganic Compound, Epitaxial Growth, Crystal Growth, Nanoparticles, Photocatalysis

\section{Introduction}

Fabrication of nanomaterials with a controllable size and shape is of great interest in many current and emerging areas of technology (Xia et al., 2003; Lou et al., 2008). Hollow micro-/nanostructures have received much attention owing to their wide applications in many fields such as catalysis, drug delivery, chemical/biological separation and sensing (Davis, 2002; Qian et al., 2007; Zhu et al., 2005). Over the past decades, many efforts have been paid to the development of different methods for the design and fabrication of hollow nanospheres and nanotubes, such as chemical vapor deposition (Goldberger et al., 2003; Zhan et al., 2004) layer-by-layer technique (Caruso et al., 1998; Caruso, 2001), sacrificed template method (Lou and Archer, 2008; Qian et al., 2006; Van Bommel et al., 2003), microemulsion (Lin et al., 2008; Schacht et al., 1996), polymer/surfactant soft templates techniques (Li et al., 2003; Yu et al., 2006), etc. Plasmonic Ag composites are promising candidates for highly efficient, active and stable photocatalysts under visible light due to Ag strong Surface Plasmon Resonance (SPR); which has been widely applied in optical and imaging fields, photothermal cancer therapy and high electro-oxidation activity etc., (Skrabalak et al., 2008; Jain et al., 2008; Huang et al., 2006; Tian et al., 2007). Recently, sliver halides/Ag photocatalysts have been widely used to photodegradation towards organic dyes due to their stability (Yu et al., 2006; Jiang and Zhang, 2011; An et al., 2010; Cheng et al., 2011). However, it is still a challenge and hot topic to search for the large-scale synthesis of silver halide with well controlled size and morphology. $\mathrm{Up}$ to date, the plasmonic catalyst $\mathrm{AgCl} / \mathrm{Ag}$ hollow nanostructures have not been achieved so far.

Herein, a facile hard template process has been developed to synthesize plasmonic photocatalyst $\mathrm{AgCl}$ hollow nanospheres using $\left[\mathrm{Ag}\left(\mathrm{NH}_{3}\right)_{2}\right] \mathrm{Cl}$ as starting material. Epitaxial growth of $\mathrm{AgCl}$ layer on the surface of silica nanospheres was carried out via $\mathrm{NH}_{3}$ volatizing to atmosphere from the mixture solution of $\left[\mathrm{Ag}\left(\mathrm{NH}_{3}\right)_{2}\right] \mathrm{Cl}$ to form $\mathrm{SiO}_{2} @ \mathrm{AgCl}$ core-shell nanospheres. Finally, $\mathrm{AgCl}$ hollow nanospheres were achieved while the silica templates were removed using HF solution. Ag nanoparticles could be in-situ formed on the backbone of the $\mathrm{AgCl}$ hollow nanospheres by converting some $\mathrm{Ag}$ ions to $\mathrm{Ag}^{0}$ species via visible light irradiation (Lu et al., 2013; An et al., 2012; Feng et al., 2012). The total synthetic process and the mechanism for the formation of the $\mathrm{AgCl} / \mathrm{Ag}$ hollow nanospheres were shown in Fig. 1. 


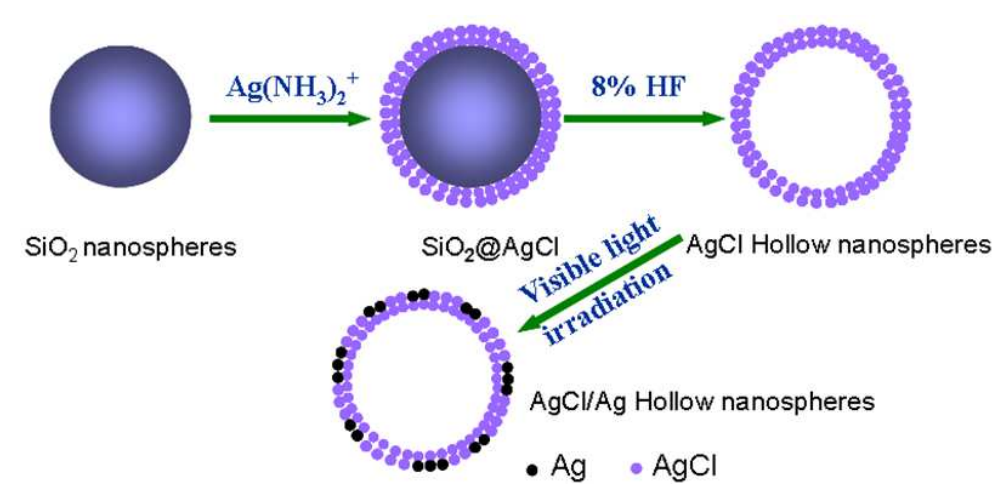

Fig. 1. Schematic illustration of formation of $\mathrm{AgCl}$ and the plasmonic photocatalyst $\mathrm{AgCl} / \mathrm{Ag}$ hollow nanospheres

\section{Experimental}

All Chemicals are of Analytic Grade and Used as Received.

In a typical synthetic process, $2 \mathrm{~mL}$ Tetraethyl Orthosilicate (TEOS) and $1 \mathrm{~mL}$ distilled water were added into $20 \mathrm{~mL}$ absolute ethanol to form clear solution in a bottle; and then $2 \mathrm{~mL}$ ammonium hydroxide was dropwise added into the former solution and stirred vigorously for $24 \mathrm{~h}$. Subsequently, the product in white was collected by centrifugation and washed three times with absolute alcohol and distilled water; respectively. Finally, it was dried at $60^{\circ} \mathrm{C}$ for $6 \mathrm{~h}$.

About $0.5 \mathrm{~g}$ amorphous silica nanospheres were dispersed with $10 \mathrm{~mL}$ water and stirred vigorously in a $50 \mathrm{~mL}$ wide-necked bottle; and then $1 \mathrm{mmol}$ of $\mathrm{AgNO}_{3}$ and $1 \mathrm{mmol}$ of $\mathrm{NaCl}$ were added into the above dispersed silica solution. Subsequently, $3 \mathrm{~mL}$ of ammonia solution $(25-28 \%$, wt $\%)$ was added into the previous mixed solution; and the total mixture solution was sonicated for $10 \mathrm{~min}$ and kept stirring vigorously for $6 \mathrm{~h}$. The product was collected by centrifugation and washed three times with double distilled water. Finally, $0.2 \mathrm{~g}$ of the product was dispersed with $5 \mathrm{~mL}$ distilled water and $2 \mathrm{~mL}$ of $8 \%$ $\mathrm{HF}$ solution was added into the solution and kept at room temperature for $6 \mathrm{~h}$ to remove the silica templates. The final product was collected by centrifugation and washed with water for three times and then dried at $60^{\circ} \mathrm{C}$ for $6 \mathrm{~h}$.

The morphology and size of the samples were investigated by Field-Emission Scanning Electron Microscopy (FESEM, JEOL-6700F); and UV-vis spectroscopy was recorded on Shimadzu spectrophotometer (2501 PC model, Kyoto, Japan), respectively. The phase of the as-prepared product was characterized by X-Ray power Diffraction (XRD) analyses, which was carried out on a Philips X'Pert PRO SUPER X-ray diffractometer equipped with graphite monochromatized $\mathrm{Cu} \mathrm{K} \alpha$ radiation and the operation voltage and current were maintained at $40 \mathrm{kV}$ and 40
$\mathrm{mA}$, respectively. The photocatalytic activity of the asprepared samples was evaluated by the degradation of $\mathrm{RhB}$ under visible light irradiation of $250 \mathrm{w}$ Xe lamp with Uv cut off filter. The degradation of Rhodamine (RhB) was carried out in a $100 \mathrm{~mL}$ beaker containing $50 \mathrm{~mL} \mathrm{RhB}$ with a concentration of $1 \times 10^{-5} \mathrm{~mol} \mathrm{~L}^{-1}(4.8$ $\mathrm{mg} \mathrm{L}^{-1}$ ) and $40 \mathrm{mg}$ of the as-prepared $\mathrm{AgCl}$ hollow nanospheres with vigorous magnetic stirring at room temperature under visible light irradiation for given time interval. The concentration of $\mathrm{RhB}$ was measured by UV-vis spectrophotometer at given interval during the degradation process of $\mathrm{RhB}$.

\section{Results and Discussion}

The first step of the synthesis of $\mathrm{AgCl}$ hollow nanospheres involved the production of uniform silica nanospheres according to the modified protocol (Stöber et al., 1968). Figure $2 \mathrm{a}$ and b show typical FESEM images of the as-prepared silica nanospheres with $220 \mathrm{~nm}$ in diameter. The phase of the as-prepared product was investigated by X-Ray Diffraction (XRD) analyses.

Figure 3 displays the XRD patterns of the asprepared samples obtained from $1 \mathrm{mmol}$ of $\mathrm{AgNO}_{3}$ and 1 $\mathrm{mmol}$ of $\mathrm{NaCl}$ and $3 \mathrm{~mL}$ of ammonia solution $(25-28 \%$, $\mathrm{wt} \%$ ) in presence of $0.5 \mathrm{~g}$ silica nanospheres at room temperature for $6 \mathrm{~h}$ according to schematic illustration shown in Fig. 1; in which all the diffraction peaks can be identified to cubic $\mathrm{AgCl}$ (JCPDS no. 31-1238) with a cell constant $\mathrm{a}=5.549 \AA$ and the broad peak around $23^{\circ}$ corresponding to amorphous silica.

Figure $4 \mathrm{a}$ and $\mathrm{b}$ show the FESEM images of the asprepared $\mathrm{SiO}_{2} @ \mathrm{AgCl}$ core-shell nanospheres; which are consisted of uniform nanospheres with similar size and rougher surface than the $\mathrm{SiO}_{2}$ nanospheres. $\mathrm{AgCl}$ hollow nanospheres could be obtained by removal the hard template using $8 \% \mathrm{HF}$ solution. As shown in Fig. 4c-d, uniform nanospheres with $220 \mathrm{~nm}$ in diameter and shellthickness of $c a .10 \mathrm{~nm}$ were obtained and no free nanoparticles could be found elsewhere. 

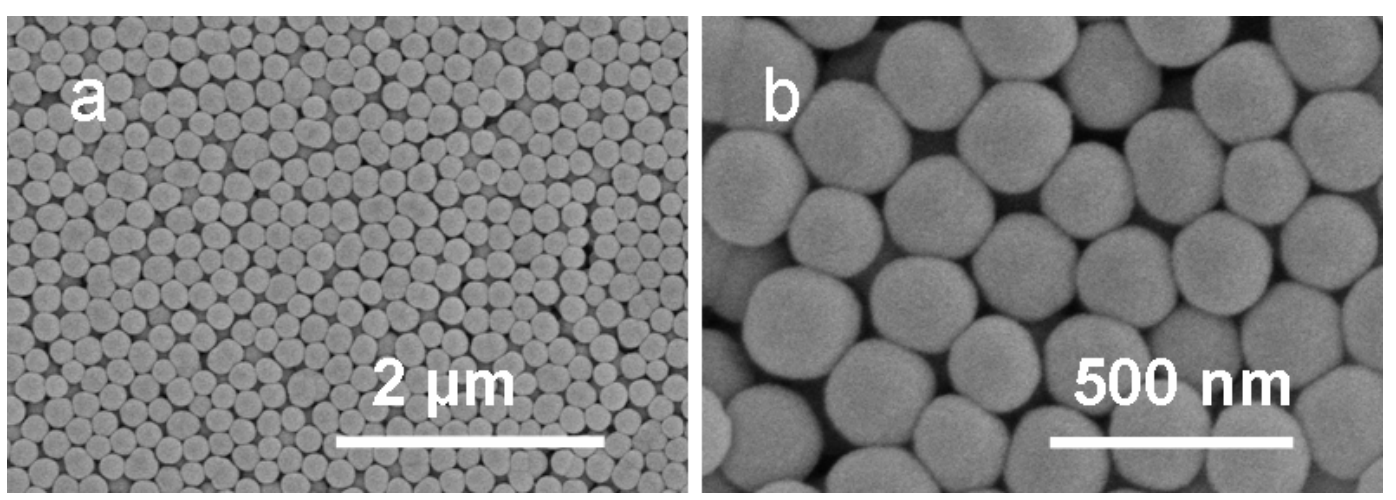

Fig. 2. FESEM images of silica amorphous nanospheres (a-b)

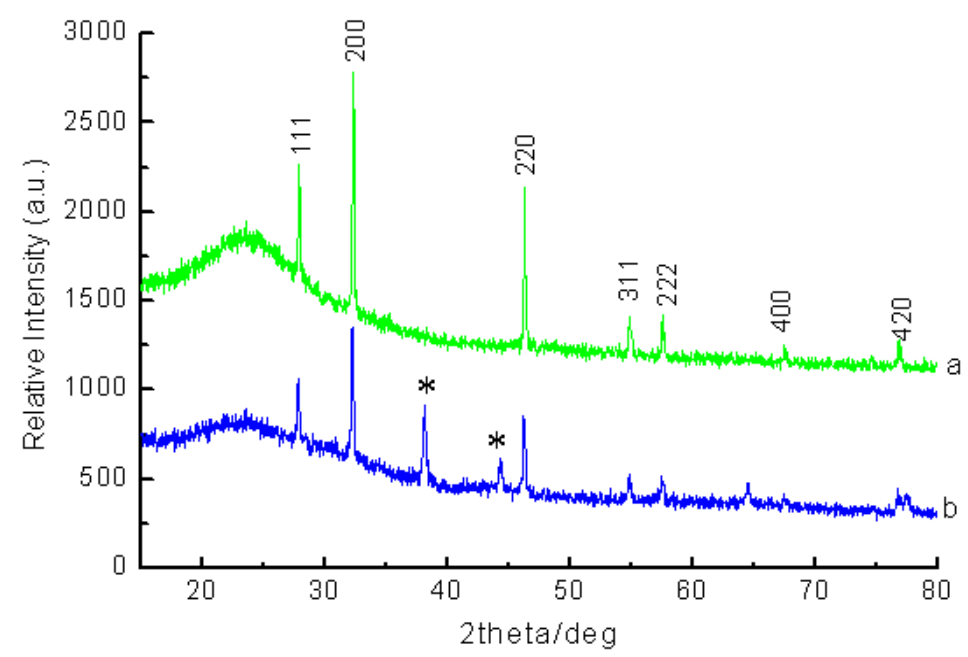

Fig. 3. XRD patterns of the as-prepared samples obtained from $1 \mathrm{mmol}$ of $\mathrm{AgNO}_{3}$ and $1 \mathrm{mmol}$ of $\mathrm{NaCl}$ and $3 \mathrm{~mL}$ of ammonia solution in presence of $0.5 \mathrm{~g}$ silica nanospheres at room temperature for $6 \mathrm{~h}$ (a); and the as-prepared photocatalysts after irradiation by Xe lamp
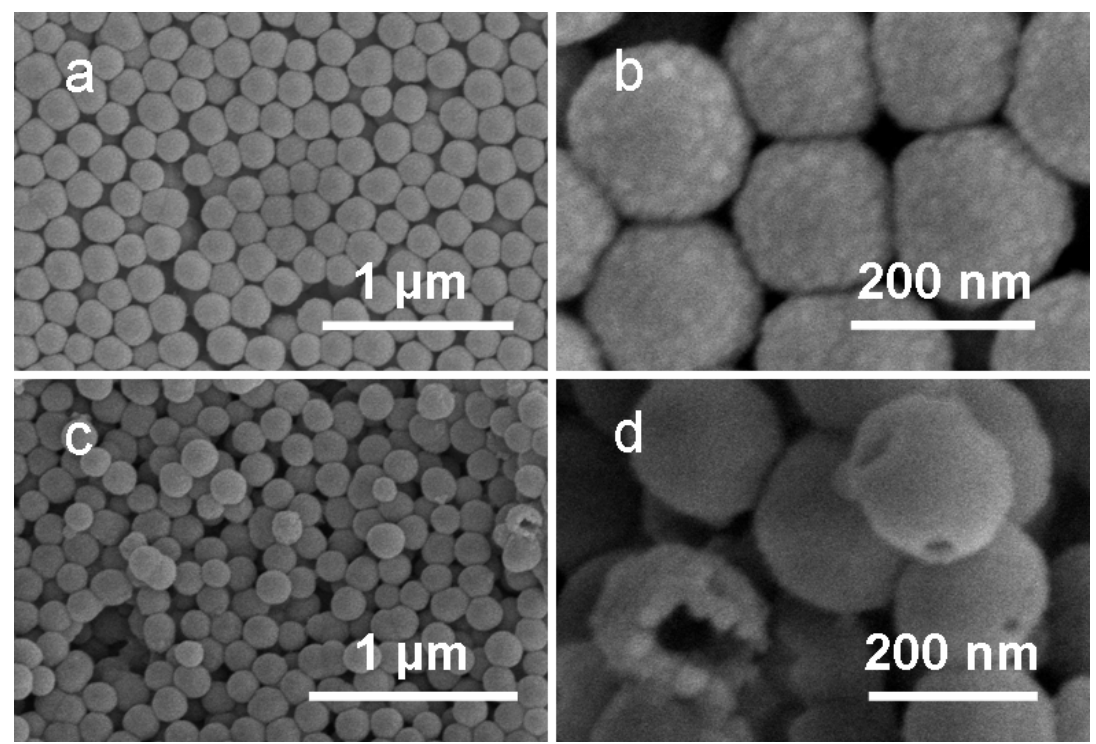

Fig. 4. $\left(\mathrm{a}\right.$ and b) FESEM images of the $\mathrm{SiO}_{2} @ \mathrm{AgCl}$ core-shell nanospheres ( $\mathrm{c}$ and d) FESEM images of the AgCl hollow nanospheres 


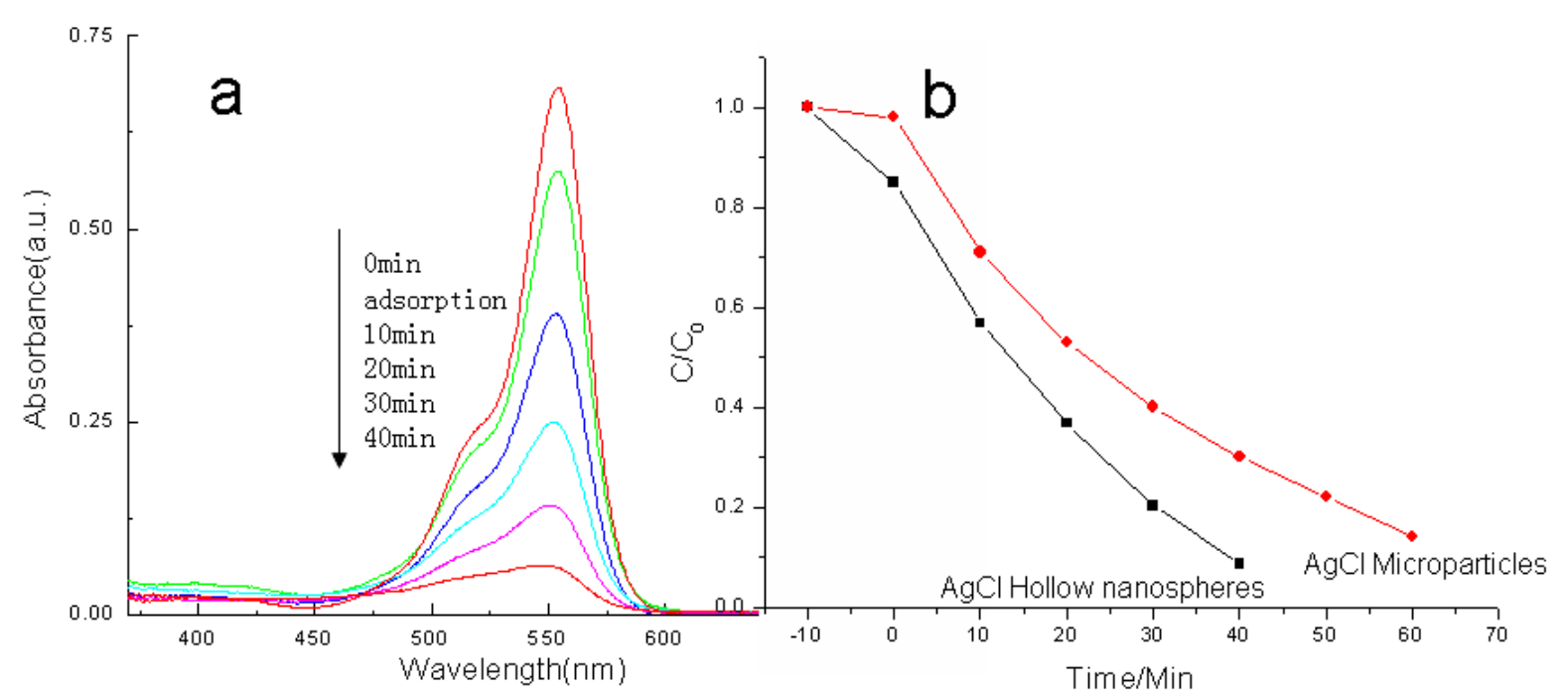

Fig. 5. UV-vis spectra showing photodecomposition of $\mathrm{RhB}$ dye in solution over the as-prepared AgCl hollow nanospheres (40 mg) under visible light irradiation and the relationship of degradation rate of $\mathrm{RhB}$ with the irradiation time

Figure 5 displayed the photodegradation behaviors of $\mathrm{RhB}$ solution $\left(4.8 \mathrm{mg} \mathrm{L}{ }^{-1}, 50 \mathrm{~mL}\right.$ ) over the $\mathrm{AgCl}$ hollow nanospheres under visible light irradiation of $250 \mathrm{w}$ Xe lamp. The characterized peak located at 553 $\mathrm{nm}$ for $\mathrm{RhB}$ dye in UV-vis spectra was used to evaluate their photodegradation at given time interval. The complete photodegradation of RhB solution (4.8 $\mathrm{mg} \mathrm{L} \mathrm{L}^{-1}, 50 \mathrm{~mL}$ ) only requires $40 \mathrm{~min}$ over the asprepared $\mathrm{AgCl}$ hollow nanospheres, suggesting the asprepared $\mathrm{AgCl}$ photocatalyst has more excellent catalytic performance toward the $\mathrm{RhB}$ solution than our previous $\mathrm{Ag}_{2} \mathrm{WO}_{4} / \mathrm{AgCl}$ photocatalyst (Liu et al., 2013). For comparison, the complete photodegradation of $\mathrm{RhB}$ solution $\left(4.8 \mathrm{mg} \mathrm{L}^{-1}, 50\right.$ $\mathrm{mL}$ ) requires more than $60 \mathrm{~min}$ for the $\mathrm{AgCl}$ microparticles as revealed by our previous study. The as-prepared $\mathrm{AgCl}$ photocatalyst has remarkable photocatalytic activity because Ag nanoparticles can trap electrons; and then facilitate the separation of photo-generated electron-hole pairs and enhance photocatalytic efficiency by converting some $\mathrm{Ag}$ ions to $\mathrm{Ag}^{0}$ species via visible light irradiation (Feng et al., 2012; Darroudi et al., 2012). As shown in Fig. 2b, the peaks located at $38.2,44.3,64.3^{\circ}$ could be indexed to the cubic Ag (JCPDS no. 87-0597) with a cell constant $\mathrm{a}=4.086 \AA$, which revealed that Ag phase has been observed and formed after visible light irradiation.

\section{Conclusion}

In summary, plasmonic photocatalyst $\mathrm{AgCl}$ hollow nanospheres have been fabricated successfully via a hard template process. The results reveal that the $\mathrm{AgCl}$ hollow nanospheres are with $220 \mathrm{~nm}$ in diameter and 10 $\mathrm{nm}$ in shell-thickness. The as-prepared $\mathrm{AgCl}$ hollow nanospheres exhibit enhanced photodegradation of RhB dye under visible light irradiation due to the Surface Plasmon Resonance (SPR) absorption and remarkable photocatalytic activity of the new Ag phase derived from photodecomposition of $\mathrm{AgCl}$ by photoirradiation. The $\mathrm{AgCl}$ hollow nanospheres will be of great importance due to potential applications in optical and imaging field, photothermal cancer therapy.

\section{Acknowledgement}

This work was financial supported by the National Science Foundation of China (Grants No. 21101140, 21471043) and start-up funding from Hefei University of Technology.

\section{Author's Contributions}

Jing Chen: Synthesized the $\mathrm{AgCl}$ hollow nanospheres.

Yuling Zhao: Synthesized silica nanospheres.

Xinhui Liu: Operated the SEM images for the products.

Fang Li: Performed the photocatalytic experiments.

Haisheng Qian: Conceived the research and designed the experiments and wrote the paper.

\section{Ethics}

This article is original and contains unpublished material. The corresponding author confirms that all of the other authors have read and approved the manuscript and no ethical issues involved. 


\section{References}

An, C.H., S. Peng and Y.G. Sun, 2010. Facile synthesis of sunlight-driven $\mathrm{AgCl}: \mathrm{Ag}$ plasmonic nanophotocatalyst. Adv. Mater., 22: 2570-2574. DOI: 10.1002/adma.200904116

An, C.H., X.J. Ming, J.Z. Wang and S.T. Wang, 2012. Construction of magnetic visible-light-driven plasmonic $\quad \mathrm{Fe}_{3} \mathrm{O}_{4} @ \mathrm{SiO}_{2} @ \mathrm{AgCl}$ : $\mathrm{Ag}$ nanophotocatalyst. J. Mater. Chem., 22: 5171-5176. DOI: 10.1039/C2JM16622D

Caruso, F., 2001. Nanoengineering of particle surfaces. Adv. Mater., 13: 11-22. DOI: 10.1002/15214095(200101)13:1<11::AID-ADMA11>3.0.CO;2-N

Caruso, F., R.A. Caruso and H. Mohwald, 1998. Nanoengineering of inorganic and hybrid hollow spheres by colloidal templating. Science, 282: 1111-1114. DOI: $10.1126 /$ science.282.5391.1111

Cheng, H.F., B.B. Huang, P. Wang, Z.Y. Wang and Z.Z. Lou et al., 2011. In situ ion exchange synthesis of the novel $\mathrm{Ag} / \mathrm{AgBr} / \mathrm{BiOBr}$ hybrid with highly efficient decontamination of pollutants. Chem. Commu., 47: 7054-7056. DOI: $10.1039 / \mathrm{C} 1 \mathrm{CC} 11525 \mathrm{~A}$

Darroudi, M., A.K. Zak, M.R. Muhamad, N.M. Huang and M. Hakimi, 2012. Green synthesis of colloidal silver nanoparticles by sonochemical method. Mater. Lett., 66: 117-120.

DOI: 10.1016/j.matlet.2011.08.016

Davis, M.E., 2002. Ordered porous materials for emerging applications. Nature, 417: 813-821. DOI: 10.1038 /nature00785

Feng, M., M. Zhang, J.M. Song, X.G. Li and S.H. Yu, 2012. Ultralong silver trimolybdate nanowires: Synthesis, phase transformation, stability and their photocatalytic, optical and electrical properties. ACS Nano, 5: 6726-6735.

DOI: $10.1021 / \mathrm{nn} 202296 \mathrm{~h}$

Goldberger, J., R.R. He, Y.F. Zhang, S.K. Lee and H.Q. Yan et al., 2003. Single-crystal gallium nitride nanotubes. Nature, 422: 599-602. DOI: $10.1038 /$ nature 01551

Huang, X.H., I.H. EI-Sayed, W. Qian and M.A. EISayed, 2006. Cancer cell imaging and photothermal therapy in the near-infrared region by using gold nanorods. J. Am. Chem. Soc., 128: 2115-2120. DOI: $10.1021 / \mathrm{ja} 057254 \mathrm{a}$

Jain, P.K., X.H. Huang, I.H. EI-Sayed and M.A. EI-Sayed, 2008. Noble metals on the nanoscale: Optical and photothermal properties and some applications in imaging, sensing, biology and medicine. Acc. Chem. Res., 41: 1578-1586.

DOI: $10.1021 / \operatorname{ar} 7002804$
Jiang, J. and L.Z. Zhang, 2011. Rapid microwaveassisted nonaqueous synthesis and growth mechanism of $\mathrm{AgCl} / \mathrm{Ag}$ and its daylight-driven plasmonic photocatalysis. Chem. Eur. J., 17: 3710-3717. DOI: 10.1002/chem.201002951

Li, Z.Q., Y. Xie, Y.J. Xiong and R. Zhang, 2003. A novel non-template solution approach to fabricate $\mathrm{ZnO}$ hollow spheres with a coordination polymer as a reactant. New J. Chem., 27: 1518-1521. DOI: $10.1039 / \mathrm{B} 304787 \mathrm{C}$

Lin, G.F., J.W. Zheng and R. Xu, 2008. Template-free synthesis of uniform CdS hollow nanospheres and their photocatalytic activities. J. Phys. Chem. C, 112: 7363-7370. DOI: 10.1021/jp8006969

Liu, X.H., J.L. Hu, J.J. Li, Y. Hu and Y. Shao et al., 2013. Facile synthesis of $\mathrm{Ag}_{2} \mathrm{WO}_{4} / \mathrm{AgCl}$ nanorods for excellent photocatalytic. Mater. Lett., 91: 129-132. DOI: 10.1016/j.matlet.2012.09.078

Lou, X.W. and L.A. Archer, 2008. A general route to nonspherical anatase $\mathrm{TiO}_{2}$ hollow colloids and magnetic multifunctional particles. Adv. Mater., 20: 1853-1858. DOI: 10.1002/adma.200702379

Lou, X.W., L.A. Archer and Z. Yang, 2008. Hollow micro-/nanostructures: Synthesis and applications. Adv. Mater., 20: 3987-4019.

DOI: 10.1002/adma.200800854

Lu, W.B., X.Y. Qin, H.Y. Li, A.M. Asiri and A.O. AlYoubi et al., 2013. One-step hydrothermal synthesis of $\mathrm{Ag}$ nanoparticle decorated submicrometer-scale spherical AgBr colloids: A highly efficient visible light plasmonic photocatalyst for degradation of organic dyes. Part. Part. Syst. Charact., 30: 67-71. DOI: $10.1002 /$ ppsc. 201200033

Qian, H.S., M. Antonietti and S.H. Yu, 2007. Hybrid "golden fleece": Synthesis and catalytic performance of uniform carbon nanofibers and silica nanotubes embedded with a high population of noble-metal nanoparticles. Adv. Funct. Mater., 17: 637-643. DOI: 10.1002/adfm.200600657

Qian, H.S., S.H. Yu, L. Ren, Y.P. Yang and W. Zhang, 2006. Synthesis of uniform carbon@silica nanocables and luminescent silica nanotubes with well controlled inner diameters. Nanotechnology, 17: 5995-5999. DOI: $10.1088 / 0957-4484 / 17 / 24 / 015$

Schacht, S., Q. Huo, I.G. Voigt-Martin, C.D. Stucky and F. Schüth, 1996. Oil-water interface templating of mesoporous macroscale structures. Science, 273: 768-771. DOI: $10.1126 /$ science. 273.5276 .768

Skrabalak, S.E., J.Y. Chen, Y.G. Sun, X.M. Lu, and L. $\mathrm{Au}$ et al., 2008. Gold nanocages: Synthesis, properties and applications. Acc. Chem. Res., 41: 1587-1595. DOI: 10.1021/ar800018v 
Stöber, W., A. Fink and E. Bohn, 1968. Controlled growth of monodisperse silica spheres in the micron size range. J. Colloid Interf. Sci., 26: 62-69. DOI: 10.1016/0021-9797(68)90272-5

Tian, N., Z.Y. Zhou, S.G. Sun, Y. Ding and Z.L. Wang, 2007. Synthesis of tetrahexahedral platinum nanocrystals with high-index facets and high electro-oxidation activity. Science, 316: 732-735. DOI: $10.1126 /$ science. 1140484

Van Bommel, K.J.C., A. Friggeri and S. Shinkai, 2003. Organic templates for the generation of inorganic materials. Angew. Chem. Int. Ed., 42: 980-999. DOI: 10.1002/anie.200390284

Wang, P., B.B. Huang, X.Y. Qin, X.Y. Zhang and Y. Dai et al., 2008.Ag@AgCl: A highly efficient and stable photocatalyst active under visible light. angew. Chem. Int. Ed., 47: 7931-7933. DOI: 10.1002 /anie. 200802483
Xia, Y., P. Yang, Y. Sun, Y. Wu and B. Mayer et al., 2003. One-dimensional nanostructures: Synthesis, characterization and applications. Adv. Mater., 15: 353-389. DOI: 10.1002/adma.200390087

Yu, J.G., H. Guo, S.A. Davis and S. Mann, 2006. Fabrication of hollow inorganic microspheres by chemically induced self-transformation. Adv. Funct. Mater., 16: 2035-2041.

DOI: $10.1002 / \mathrm{adfm} .200600552$

Zhan, J.H., Y. Bando, J.Q. Hu, Y.B. Li and D. Golberg, 2004. Synthesis and field-emission properties of $\mathrm{Ga}_{2} \mathrm{O}_{3}-\mathrm{C}$ nanocables. Chem. Mater., 16: 5158-5161. DOI: $10.1021 / \mathrm{cm} 048909 \mathrm{u}$

Zhu, Y.F., J.L. Shi, W.H. Shen, X.P. Dong and J.W. Feng et al., 2005. Stimuli-responsive controlled drug release from a hollow mesoporous silica sphere/polyelectrolyte multilayer core-shell structure. Angnew. Chem. Int. Edit., 44: 5083-5087. DOI: 10.1002/anie. 200501500 